\title{
Measuring Vertical and Horizontal Intra-Industry Trade: The Case for Turkey
}

\author{
Güzin Erlat \\ Middle East Technical University \\ Haluk Erlat \\ Middle East Technical University \\ Demet Senoglu \\ Middle East Technical University
}

Follow this and additional works at: https://ecommons.luc.edu/meea

Part of the Economics Commons

\section{Recommended Citation}

Erlat, Güzin; Erlat, Haluk; and Senoglu, Demet, "Measuring Vertical and Horizontal Intra-Industry Trade: The Case for Turkey". Topics in Middle Eastern and North African Economies, electronic journal, 9, Middle East Economic Association and Loyola University Chicago, 2007, http://www.luc.edu/orgs/meea/

This Article is brought to you for free and open access by the Journals and Magazines at Loyola eCommons. It has been accepted for inclusion in Topics in Middle Eastern and North African Economies by an authorized administrator of Loyola eCommons. For more information, please contact ecommons@luc.edu. (C) 2007 the authors 


\title{
MEASURING VERTICAL AND HORIZONTAL INTRA- INDUSTRY TRADE: THE CASE FOR TURKEY
}

\author{
GüZin ERLAT, HALUK ERLAT AND DEMET ŞENOĞLU \\ Department of Economics \\ Middle East Technical University \\ 06531 Ankara, Turkey \\ Fax: 90-312-2107964 \\ Email: gerlat@metu.edu.tr \\ Email: herlat@metu.edu.tr
}

Prepared for presentation at the $6^{\text {th }}$ International Conference of the Middle East Economic Association, March 14-16, 2007, Zayed University, Dubai. 


\section{Introduction}

In an earlier study (Erlat and Erlat, 2003) we considered the measurement of intraindustry trade (IIT) for the Turkish manufacturing industry using 3-digit SITC, Rev. 3 data and also focused on the share of intra-industry trade in new trade; namely, marginal intraindustry trade (MIIT). But in those measurements, we had not differentiated between the trade of goods of similar quality and the trade of goods of different quality. The first type of IIT is called horizontal IIT (HIIT) while the second type is referred to as vertical IIT (VIIT). It is found that VIIT is almost always dominant in the IIT of all countries, be they developed or less developed. This dominance, however, is weaker in developed countries, (see, e.g., Greenaway et al (1994) for the UK) as opposed to less developed or emerging market economies (see, e.g. Aturupane, Djankov and Hoekman (1999) for the Eastern European countries). For Turkey, being an emerging market economy, the VIIT component would be expected to be more important.

In fact, in two studies of a rather limited nature (Erk and Tekgul, 2001 and Lohrman, 2002) this was the conclusion reached. These studies, however, covered a rather short period (1993-1999 for Erk and Tekgul, 1991, 1995, 1999 for Lohrman) and did not utilize trade data at as low a level of aggregation possible so that it corresponds to "goods" rather than "sectors". In the present study, we intend to make up for both of these shortcomings by using SITC, Rev. 3 data at the 5-digit level and by covering a substantially longer period, namely 1987-2001.

Hence, in Section 2 we describe the methodology utilized. In Section 3 the data are explained and, in Section 4, the empirical results are presented. The conclusions are given in Section 5 .

\section{Methodology}

There, apparently, are two competing methods to decide the rate of intra-industry trade (IIT). One is due to Grubel and Lloyd (1971) (GL) and the other, to Fontagné and Freudenberg (1997) (FF). The GL approach is based on measuring the trade overlap for a given industry. Letting $X_{i j t}$ stand for the exports of good $i$ of industry $j$ at time $t$ and $M_{i j t}$ stand for the import of this good for industry $j$, at $t$, the GL index for the $i^{\text {th }}$ good is obtained as 


$$
G L_{i j t}=1-\frac{\left|X_{i j t}-M_{i j t}\right|}{X_{i j t}+M_{i j t}}, \quad i=1, \ldots, n_{j} ; j=1, \ldots, N ; t=1, \ldots, T
$$

and lies between 0 and 1, with values close to unity indicating a high rate of IIT for good $i$. On the other hand, the FF index is based on comparing the extent to which the minimum of the pair $\left(X_{i j t}, M_{i j t}\right)$ covers the maximum. Formally, the $j^{\text {th }}$ good is taken to exhibit a meaningful level of IIT if

$$
F F=\frac{\min \left(X_{i j t}, M_{i j t}\right)}{\max \left(X_{i j t}, M_{i j t}\right)} \geq \xi
$$

where $\xi$ is suggested by FF to be $10 \%$.

However, in decomposing IIT into vertical (VIIT) and horizontal (HIIT) components, both approaches use the same criterion. They follow Abd-el-Rahman (1991) in first obtaining the unit values of $X_{i j t}$ and $M_{i j t}$, which we shall denote by $U V X_{i j t}$ and $U V M_{i j t}$, then forming their ratios $U V X_{i j t} / U V M_{i j t}$ and, based on a dispersion factor, $\alpha$, deciding if an industry exhibits HIIT when

$$
1-\alpha \leq \frac{U V X_{i j t}}{U V M_{i j t}} \leq 1+\alpha
$$

and exhibits VIIT when

$$
\frac{U V X_{i j t}}{U V M_{i j t}}\left\langle 1-\alpha \quad \text { or } \quad \frac{U V X_{i j t}}{U V M_{i j t}}\right\rangle 1+\alpha
$$

In addition, the first inequality in (4) implies that VIIT is low-quality (LQVIIT) while the second inequality implies that it is high-quality (HQVIIT)

In the present paper, following Greenaway et al $(1994,1995,1999)$ we shall base our analysis on the GL approach, postponing the use of the FF index for future research. The goods will be represented by 5-digit SITC sectors. The results will be presented at various levels of aggregation. These aggregate values will simply be the weighted averages of the 
$G L_{i j t}^{1}$ where the weights are the shares of $i^{\text {th }}$ good in the total trade of whatever level of aggregation we are considering. A bit of algebra shows that this weighted average reduces to

$$
G L_{r t}=1-\frac{\sum_{i=1}^{n_{r}}\left|X_{i r t}-M_{i r t}\right|}{\sum_{i=1}^{n_{r}}\left(X_{i j t}+M_{i j t}\right)}
$$

where $r$ may stand for $j$, the 3-digit industry, or the technical categorization we shall use to present the results, or the country as a whole. Of course, $n_{r}$ will represent the number of 5digit sectors that exhibit IIT. Hence, $n_{r} \leq n_{j}$ if the aggregation is done for the $j^{\text {th }} 3$-digit sector.

The decomposition of the GL index into vertical and horizontal components, and the vertical component into high and low quality components will be done at aggregate levels. Hence, denoting the corresponding GL-indexes for VIIT and HIIT, respectively, as $G L_{r t, V}$ and $G L_{r t, H}$, we may express them as,

$$
G L_{r t, V}=1-\frac{\sum_{i=1}^{n_{r V}}\left|X_{i r t}-M_{i r t}\right|}{\sum_{i=1}^{n_{r}}\left(X_{i r t}+M_{i r t}\right)} \text { and } G L_{r t, H}=1-\frac{\sum_{i=1}^{n_{r t}}\left|X_{i r t}-M_{i r t}\right|}{\sum_{i=1}^{n_{r}}\left(X_{i r t}+M_{i r t}\right)}
$$

where $n_{r V}+n_{r H}=n_{r}$ so that $G L_{r t}=G L_{r t, V}+G L_{r t, H}$. A similar decomposition will be applied to $G L_{r t, V}$ so that $G L_{r t}$ may also be expressed as $G L_{r t}=G L_{r t, L Q V}+G L_{r t, H Q V}+G L_{r t, H}$.

\section{The Data}

The data on foreign trade have been obtained from the State Institute of Statistics. They cover the period 1987-2001 and are classified in terms of SITC, Rev. 3., at the 5-digit

\footnotetext{
${ }^{1}$ In doing so we are also heeding the warning of Greenaway and Milner (1983) to the effect that using the aggregated $X$ and $M$ values instead would lead to an upward bias in the calculation of the GL values.
} 
level. They comprise the $X$ and $M$ flows both in terms of kilograms and in terms of \$US. Unit values are obtained as the ratio of these two flows.

\section{Empirical Results}

The empirical results are presented in three levels; for the country as a whole, for a five-way classification of the trading sectors and for the sectors at the 3-digit level. All three levels of aggregation have been done using the expression in equation (5) above.

The five way classification is due to Yilmaz (2002), inspired by the work of Hufbauer and Chilas (1974), and has been used by us in previous work (e.g., Erlat and Erlat (2003), Erlat and Erlat (2006)). Hence we classify

SITC 0, 2 (ex.26), 3 (ex.35), 4, 56 as raw material intensive goods (RMIG)

SITC 26, 6 (ex.62, 67, 68), 8 (ex. 87, 88) as labour-intensive goods (LIG)

SITC 1, 35, 53, 55, 62, 67, 67, 78 as capital-intensive goods (CIG)

SITC 51, 52, 54, 58, 59, 75, 76 as easy-to-imitate research-intensive goods (EIRG)

SITC 57, 7(ex.75,76,78), 87, 88 as difficult-to-imitate research-intensive goods(DIRG)

The details of this classification are given in the Appendix.

We present the aggregate results in a series of graphs. In Figure 1, we have the GL indexes for total trade and for the five subgroups specified above. We note that IIT for the country as a whole does not exceed 30\% and its highest level $(27.92 \%)$ is reached in 2001. There appears to be a decline in the level of overall IIT from 1987 to 1993, showing a jump in 1994 (during which Turkey went through a financial crisis) and then starting to increase from 1995 onwards.

Of the subgroups, we find that the rate of IIT in the capital-intensive goods sectors is uniformly higher than total IIT throughout the period under consideration. It also reaches its highest level of $43.11 \%$ in 2001, but moves around 25\% from 1990 to 1998. The IIT of labour-intensive goods also moves above total IIT but never exceeds $30 \%$ and only rises above the IIT of CIG in 1991, 1997 and 1998. In fact, it shows a mild decline after 1996.

Of the subgroups with rates of IIT below total IIT, the performance of difficult-toimitate research-intensive goods is the most interesting. It starts at a level above total IIT but 
Figure 1

GL Indeces for Total and Subgroup IIT's, 1987-2001

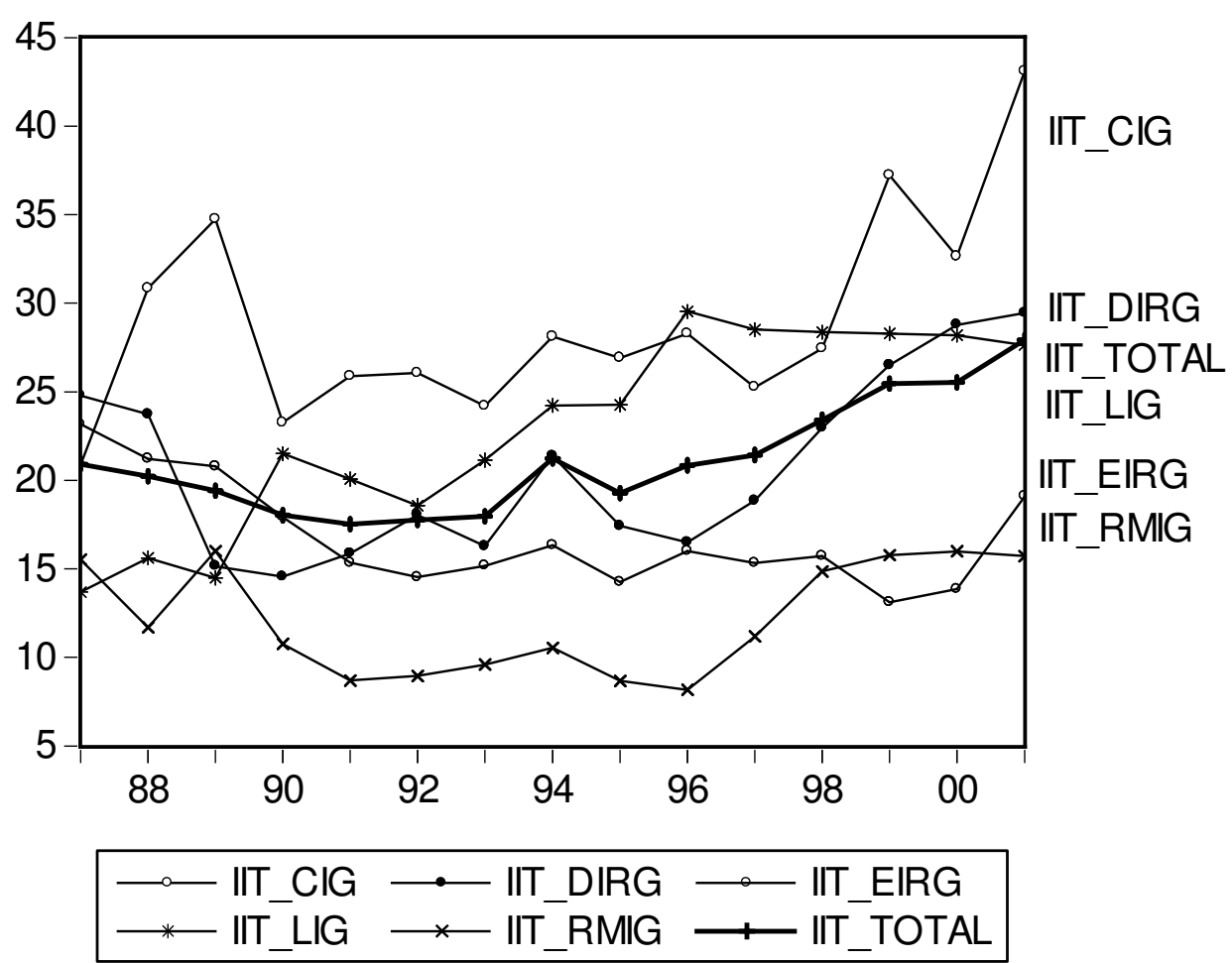

falls below it in 1984, catching up with it in 1992 and in 1994, and after declining to $16.49 \%$ in 1986, it shows steady improvement and exceeds total IIT in 1999 and continues to exceed the rate of IIT of LIG in 2000 and 2001. The IIT performance of easy-to-imitate research intensive goods lies below that of DIRG from 1993 onwards, staying around 15\% for most of the period. Finally, the performance of raw-material intensive goods is completely below total IIT for the whole period and those of the other four subgroups for most of the period. In fact, it lies slightly below 10\% from 1991 to 1996, showing some improvement until 1998 where it levels off at around $15 \%$.

Turning to the decomposition of IIT into its vertical and horizontal components, the remaining graphs contain the plots of the GL indexes for overall IIT and its decomposition into horizontal IIT and into high and low quality vertical IIT. We start, in Figure 2, with total IIT and immediately note that low quality vertical IIT dominates both high quality vertical and horizontal IIT. In fact, LQVIIT is the prime mover of the steady increase in total IIT from 1993 onwards. It reaches its highest value of $18.38 \%$ in 2001 . We also find that horizontal IIT fluctuates around 5\% and that it dominates high quality vertical IIT at almost all points. HQVIIT, in general, fluctuates between 3 and $4 \%$. 
Figure 2

Horizontal and Vertical (High and Low Quality) Decomposition for

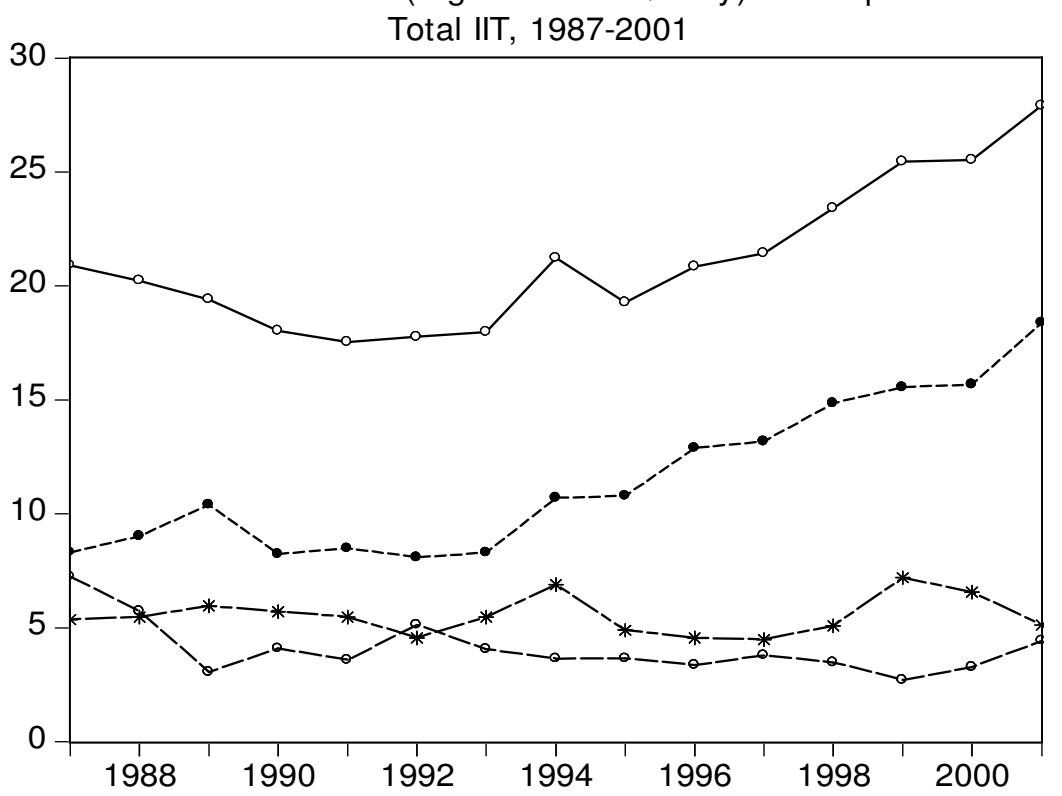

$\because$ IIT_TOTAL $\quad-\cdots--$ LQVIIT_TOTAL

HQ̄VIIT_TOTAL - * - HIIT_TOTTAL

Figure 3

Horizontal and Vertical (High and Low Quality) IIT Decomposition for

Raw Material Intensive Goods, 1987-2001

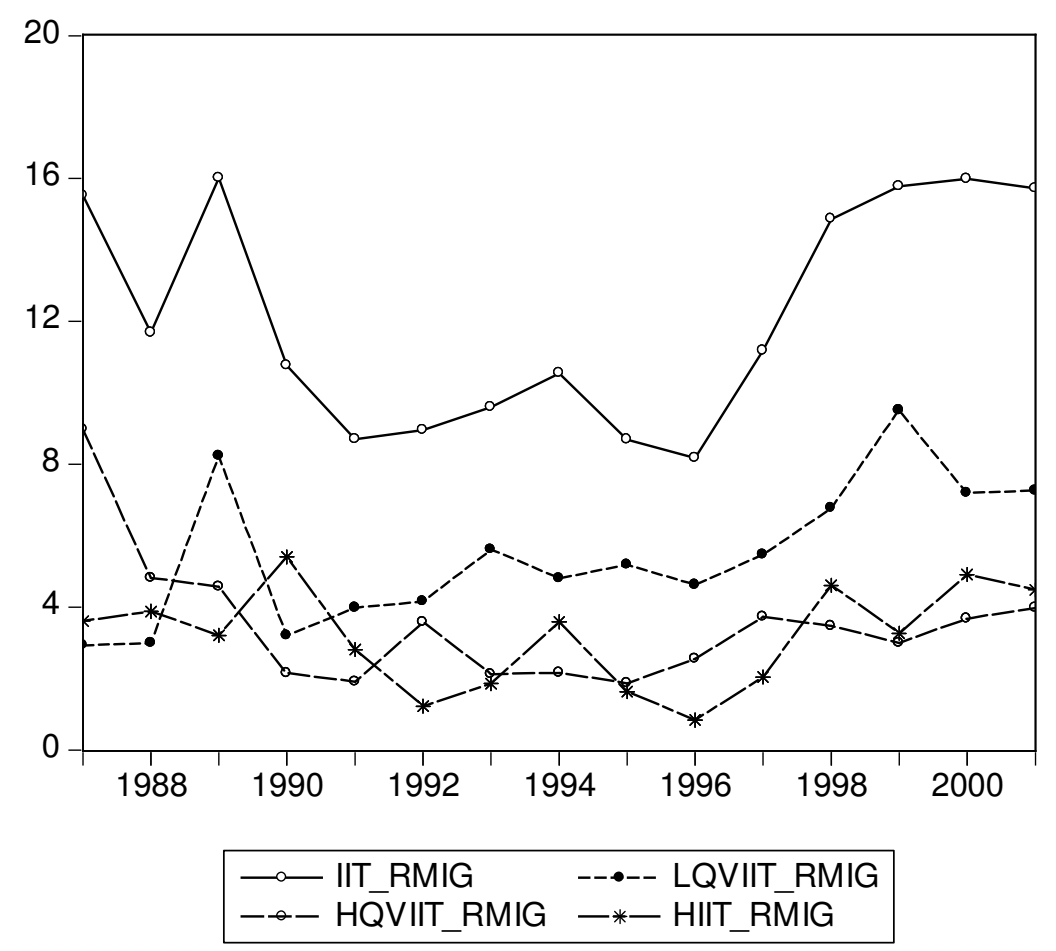


The situation for RMIG is given in Figure 3. The domination of LQVIIT is not for the period as a whole but takes place after 1991. It never exceeds $10 \%$ and reaches its highest level of $9.51 \%$ in 1999. It contributes to the upswing in IIT after 1996 but, it appears that this upswing is affected more by the increase in HIIT. In fact, HIIT overtakes HQVIIT in 1998 after this upswing and remains above it until the end of the period. But, for the period as a whole, the dominating roles of HIIT and HQVIIT change place quite often. Except for a high of $8.98 \%$ in 1987 for HQVIIT and $5.41 \%$ for HIIT in 1990, when both exceed LQVIIT, these series fluctuate around $3 \%$.

Figure 4

Horizontal and Vertical (High and Low Quality) IIT Decomposition for Labour Intensive Goods, 1987-2001

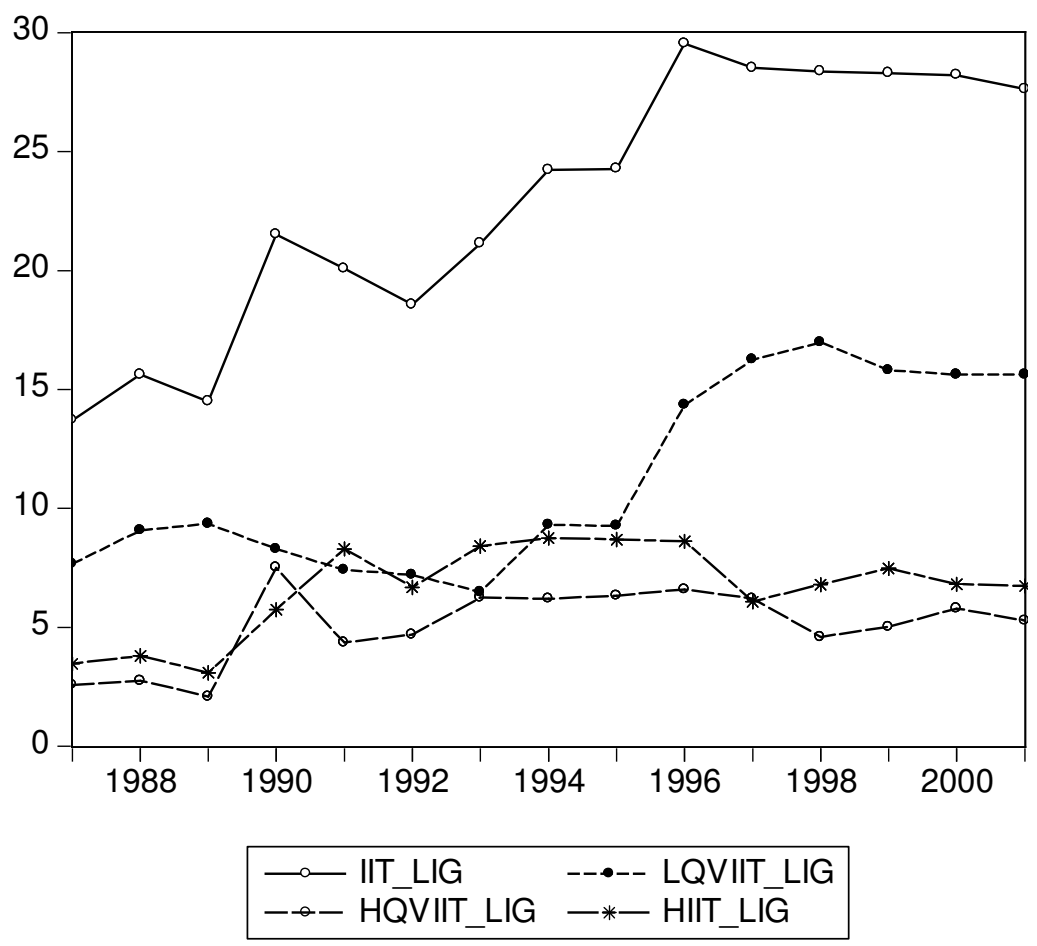

When we look at Figure 4 for LIG, we again note that LQVIIT is dominant except for 1991 and 1993 where the values of HIIT are higher. LQVIIT shows a considerable shift after 1995 and reaches $16.98 \%$ in 1998 after which it levels off at slightly below 16\%. The relationship between HIIT and HQVIIT is rather different from that of RMIG where now HIIT appears to dominate except for 1990 and 1997. HIIT reaches a high of $8.74 \%$ in 1994 while HQVIIT attains $8.28 \%$ in 1990.

In the case of CIG, from Figure 5, we note that LQVIIT becomes dominant after 1994, but during earlier sub-periods, such as 1988-1989 and 1993, HIIT exceeds LQVIIT. LQVIIT 
Figure 5

Horizontal and Vertical (High and Low Quality) IIT Decomposition for

Capital Intensive Goods, 1987-2001

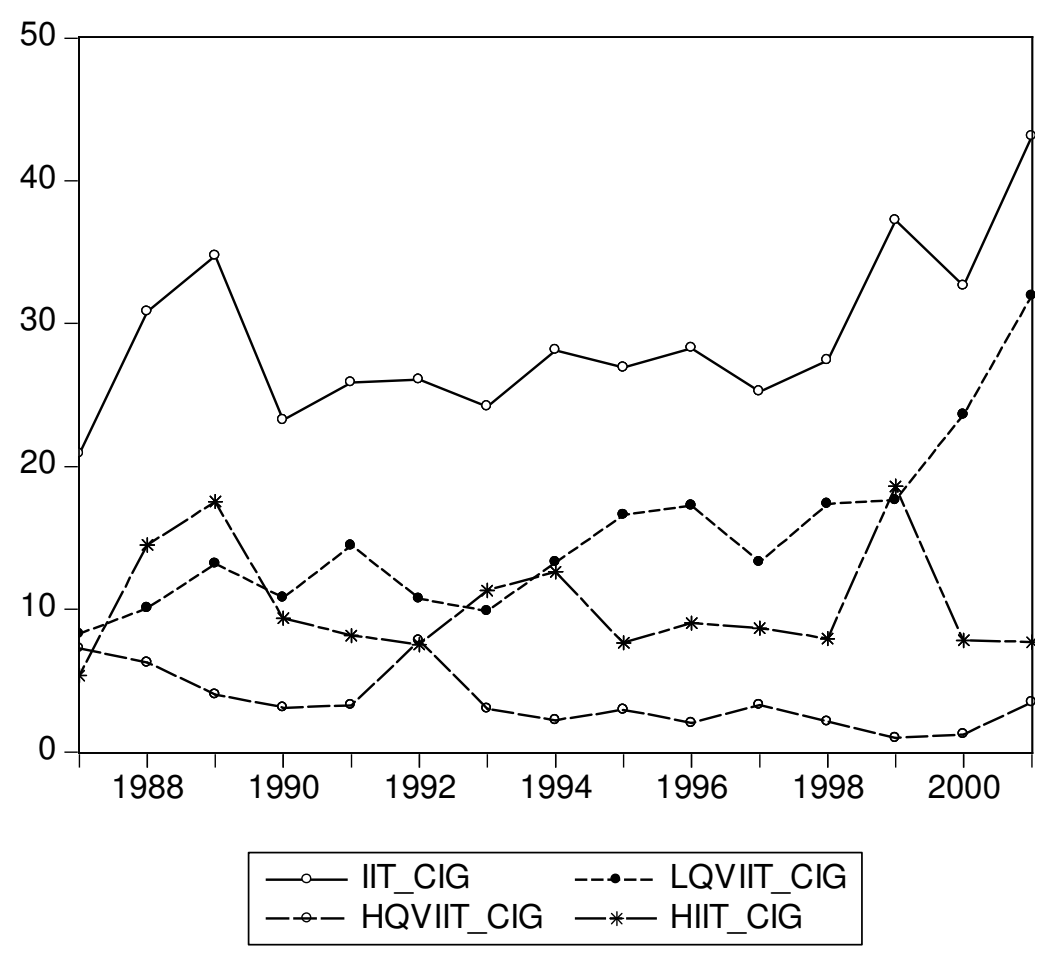

takes its highest value at the end of the period (31.92\%). HIIT, on the other hand, completely dominates HQVIIT except in 1987 and 1992. HQVIIT exhibits a slightly declining trend after 1993.

Figure 6 contains the case for EIRG. The dominance of LQVIIT is clear cut. HIIT dominates between 1989 and 1995 after which it changes places with HQVIIT and becomes dominant, once again, from 1998 onwards. Both HIIT and HQVIIT take on their highest values at the beginning of the period $(7.30 \%$ for HIIT in 1989 and $9.30 \%$ for HQVIIT in 1987).

Finally, from Figure 7, we observe a similar picture for LQVIIT in the case of DIRG, HIIT exceeding it only in 1987. Interestingly, HQVIIT now dominates HIIT until 1998 where HIIT takes over for 1999 and 2000. HQVIIT starts at a quite high level in 1987 (15.44\%) but declines rapidly to $1.98 \%$ in 1989 and generally fluctuates around $2.5 \%$. HIIT starts at a low level (1.5\%) and does not exceed this level very much until 2000 where it attains its highest level of $8.42 \%$.

The final set of aggregate results is at the 3-digit level and is presented in Table 2. In constructing this table, we first calculated the averages of their GL values for the period as a 
Figure 6

Horizontal and Vertical (High and Low Quality) IIT Decomposition for Easy to Imitate Research Intensive Goods, 1987-2001

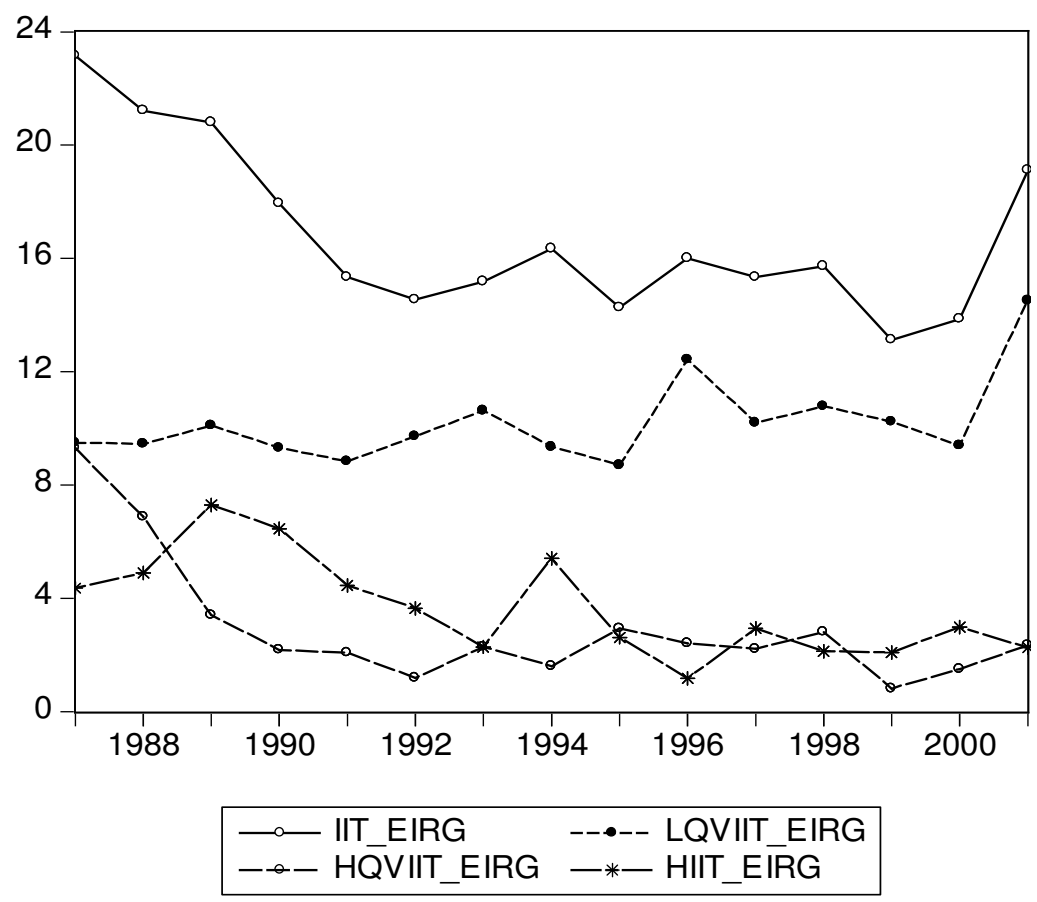

Figure 7

Horizontal and Vertical Decomposition of (High and Low Quality) IIT for Difficult-to-Imitate Research Intensive Goods, 1987-2001

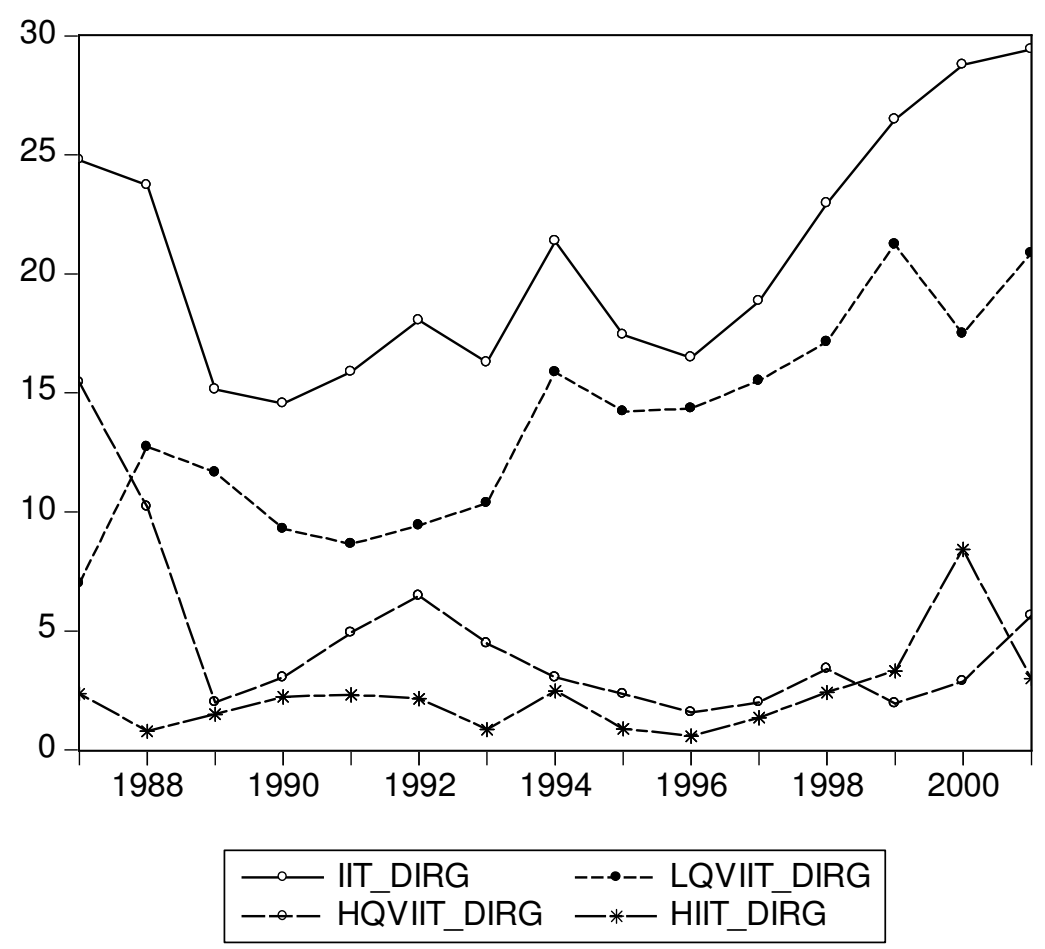


whole and for the last three years. We then chose those sectors that exceeded the larger of the corresponding full period or last three-year average GL's for total trade and for the trade of each subgroup. Finally, from among these sectors, we chose the ones that exhibited average GL values greater than $50 \%$.

\begin{tabular}{|c|c|c|c|c|c|c|}
\hline \multicolumn{7}{|c|}{ Table 1} \\
\hline \multicolumn{7}{|c|}{ Number of 3-Digit Sectors Exhibiting IIT } \\
\hline & Total & RMIG & LIG & $\mathrm{CIG}$ & EIRG & DIRG \\
\hline \# of Sectors & 257 & 79 & 62 & 37 & 27 & 52 \\
\hline \# of Sectors with IIT & 254 & 76 & 62 & 37 & 27 & 52 \\
\hline \# of Sectors with GL $>$ Means ${ }^{1}$ & 118 & 25 & 41 & 16 & 8 & 28 \\
\hline \# of Sectors with GL $>50 \%$ & 35 & 8 & 18 & 5 & 2 & 2 \\
\hline$\%^{2}$ of Sectors with IIT & 98.32 & 96.20 & 100.00 & 100.00 & 100.00 & 100.00 \\
\hline$\%$ of Sectors with GL $>$ Means & 45.91 & 31.65 & 66.13 & 43.24 & 29.63 & 53.85 \\
\hline$\%$ of Sectors with GL $>50 \%$ & 13.62 & 10.13 & 29.03 & 13.51 & 7.41 & 3.85 \\
\hline
\end{tabular}

The number of sectors involved in every stage, together with their percentages in the total number of 3-digit sectors, is given in Table 1. We note that only three sectors out of the total number of 257 have not been involved in IIT during the 1987-2001 period. 118, or $45.91 \%$ of all sectors have average GL values greater than the period and/or the last threeyearly average, but only 35 of them, or $13.62 \%$ exceed $50 \%$. This, of course, is a very low number and is echoed, to a great extent, in the subgroups. The highest such percentage is 29.03 for LIG and lowest is for DIRG at 3.85\%. Interestingly, DIRG is second only to LIG in the percent of sectors with average GL values greater than the larger of the overall and subgroup averages. The percentages associated with CIG come closest to that of all sectors.

Turning to Table 2, we find, for RMIG, that there are two sectors that exceed $50 \%$ for the period mean and for the mean of the last three years. These are " 074 Tea and mate" and "248 Wood, simply worked, and railway sleepers of wood". The remaining six sectors all only exceed the mean for the final three years. The largest improvement appears to be in "041 Wheat etc." and "016 Meat etc.". The decomposition of these sectors all indicates that VIIT is the dominant component. The breakdown of VIIT, however, does not lead to the overall dominance of LQVIIT. The GL values for LQVIIT exceed 50\% only for 041, 074, "285 Aluminium etc." and " 431 Animal or vegetable fats and oils, processed" and only for the last three years. On the other hand, HQVIIT is at about the same level as LQVIIT for 016 when the period mean is considered, but definitely dominates the last three years. HQVIIT is also 


\begin{tabular}{|c|c|c|c|c|c|c|c|c|c|c|c|}
\hline \multicolumn{12}{|c|}{ Table 2} \\
\hline \multicolumn{12}{|c|}{$\begin{array}{c}\text { Table } 2 \\
\text { 3-Digit Sectors with Average GLs Exceeding 50\% }\end{array}$} \\
\hline \multicolumn{2}{|r|}{ RMIG } & \multicolumn{2}{|c|}{\begin{tabular}{|c|} 
IIT \\
Period Mean 3-Year Mean \\
\end{tabular}} & \multicolumn{2}{|c|}{$\begin{array}{c}\text { HIIT } \\
\text { Period Mean 3-Year Mean } \\
\end{array}$} & \multicolumn{2}{|c|}{\begin{tabular}{|c|} 
VIIT \\
Period Mean 3-Year Mean \\
\end{tabular}} & \multicolumn{2}{|c|}{\begin{tabular}{c|} 
LQVIIT \\
Period Mean 3-Year Mean \\
\end{tabular}} & \multicolumn{2}{|c|}{\begin{tabular}{|c|} 
HQVIIT \\
Period Mean 3-Year Mean \\
\end{tabular}} \\
\hline 016 & Meat and edible meat offal, salted, in brine, dried or smoked; edible flours and meals of meat & 44.32 & 66.63 & 0.00 & 0.00 & 44.32 & 66.63 & 22.08 & 9.52 & 22.23 & 57.11 \\
\hline 041 & Wheat (including spelt) and meslin, unmilled & 36.85 & 64.89 & 7.84 & 0.98 & 29.01 & 63.91 & 25.72 & 63.91 & 3.29 & 0.00 \\
\hline 074 & Tea and matu & 52.84 & 74.99 & 1.73 & 0.06 & 51.11 & 74.93 & 42.55 & 61.80 & 8.56 & 13.13 \\
\hline 248 & Wood, simply worked, and railway sleepers of wood & 52.45 & 50.07 & 4.70 & 0.00 & 47.75 & 50.07 & 16.14 & 0.90 & 31.60 & 49.17 \\
\hline 285 & Aluminium ores and concentrates including alumina) & 46.21 & 52.99 & 0.00 & 0.00 & 46.21 & 52.99 & 46.05 & 52.70 & 0.16 & 0.29 \\
\hline 288 & Non-ferrous base metal waste and scrap, n.e.s. & 31.70 & 57.13 & 3.91 & 16.71 & 27.79 & 40.42 & 6.61 & 14.00 & 21.18 & 26.42 \\
\hline 291 & Crude animal materials, n.e.s. & 35.59 & 50.01 & 0.03 & 0.10 & 35.56 & 49.91 & 5.41 & 0.12 & 30.15 & 49.79 \\
\hline 431 & Animal or vegetable fats and oils, processed & 42.07 & 51.20 & 13.45 & 0.34 & 28.62 & 50.85 & 25.83 & 50.58 & 2.79 & 0.27 \\
\hline RMIG Mean & & 12.15 & 15.83 & 3.58 & 4.22 & 8.96 & 11.54 & 5.46 & 7.99 & 3.50 & 3.55 \\
\hline \multicolumn{2}{|l|}{ Overall Mean } & 21.13 & 26.30 & 5.33 & 6.30 & 15.60 & 20.00 & 11.52 & 16.53 & 4.08 & 3.47 \\
\hline & LIG & \multicolumn{2}{|c|}{\begin{tabular}{|c|} 
IIT \\
Period Mean 3-Year Mean \\
\end{tabular}} & \multicolumn{2}{|c|}{\begin{tabular}{|c|} 
HIIT \\
Period Mean 3-Year Mean \\
\end{tabular}} & \multicolumn{2}{|c|}{\begin{tabular}{c|} 
VIIT \\
Period Mean 3-Year Mean \\
\end{tabular}} & \multicolumn{2}{|c|}{\begin{tabular}{|c|} 
LQVIIT \\
Period Mean 3-Year Mean \\
\end{tabular}} & \multicolumn{2}{|c|}{\begin{tabular}{|c|} 
HQVIIT \\
Period Mean 3-Year Mean \\
\end{tabular}} \\
\hline 266 & Synthetic fibers suitable for spinning & 60.91 & 52.45 & 51.73 & 49.26 & 9.17 & 3.19 & 1.67 & 0.52 & 7.50 & 2.67 \\
\hline 635 & Wood manufactures, n.e.s. & 52.88 & 56.54 & 5.61 & 6.21 & 47.27 & 50.33 & 24.17 & 25.08 & 23.10 & 25.25 \\
\hline 642 & Paper and paperboard, cut to size or shape, and articles of paper or paperboard & 38.47 & 56.56 & 7.93 & 12.98 & 30.54 & 43.58 & 24.62 & 34.50 & 5.92 & 9.08 \\
\hline 651 & Textile yarn & 46.99 & 52.79 & 19.75 & 15.34 & 27.23 & 37.45 & 19.20 & 27.73 & 8.03 & 9.72 \\
\hline 652 & Cotton fabrics, woven (not including narrow or special fabrics) & 57.33 & 70.23 & 26.32 & 39.91 & 31.01 & 30.32 & 17.22 & 27.93 & 13.79 & 2.39 \\
\hline 653 & Fabrics woven, of man-made textile materials (not including narrow or special fabrics) & 51.47 & 61.56 & 9.78 & 15.47 & 41.69 & 46.08 & 6.20 & 8.24 & 35.49 & 37.84 \\
\hline 654 & Other textile fabrics, woven & 48.35 & 59.64 & 25.07 & 52.12 & 23.28 & 7.52 & 3.08 & 3.55 & 20.20 & 3.97 \\
\hline 655 & Knitted or crochetted fabrics (including tubular knit fabrics) & 46.19 & 50.63 & 18.06 & 3.54 & 28.14 & 47.09 & 26.06 & 47.09 & 2.08 & 0.00 \\
\hline 664 & Glass & 49.43 & 64.92 & 4.83 & 18.46 & 44.60 & 46.46 & 40.82 & 38.44 & 3.78 & 8.02 \\
\hline 666 & Pottery & 56.16 & 70.72 & 10.69 & 0.00 & 45.48 & 70.72 & 32.56 & 45.19 & 12.92 & 25.53 \\
\hline 691 & Structures and parts of structures, n.e.s., of iron, steel, or aluminium & 54.12 & 65.90 & 8.11 & 5.20 & 46.01 & 60.70 & 45.51 & 60.47 & 0.50 & 0.22 \\
\hline 692 & Metal containers for storage or transport & 61.27 & 65.55 & 6.66 & 18.99 & 54.61 & 46.56 & 50.63 & 46.56 & 3.98 & 0.00 \\
\hline 694 & Nails, screws, nuts, bolts, rivets and the like, of iron, steel, copper or aluminium & 36.69 & 62.69 & 0.00 & 0.00 & 36.69 & 62.69 & 35.95 & 62.69 & 0.74 & 0.00 \\
\hline 699 & Manufacturs of base metal, n.e.s. & 43.70 & 55.24 & 2.59 & 3.16 & 41.11 & 52.08 & 35.78 & 49.43 & 5.33 & 2.65 \\
\hline 811 & Prefabricated buildings & 57.39 & 95.40 & 6.42 & 32.10 & 50.97 & 63.30 & 50.97 & 63.30 & 0.00 & 0.00 \\
\hline 813 & Lighting fixtures and fittings, n.e.s. & 40.07 & 56.00 & 2.53 & 0.98 & 37.54 & 55.01 & 33.83 & 54.16 & 3.70 & 0.85 \\
\hline 821 & Furniture and parts thereof; bedding, mattresses, mattress supports, cushions & 51.91 & 57.77 & 2.83 & 0.06 & 49.08 & 57.71 & 48.33 & 57.71 & 0.74 & 0.00 \\
\hline 851 & Footwear & 47.75 & 70.35 & 6.83 & 0.47 & 40.92 & 69.88 & 32.36 & 69.87 & 8.56 & 0.01 \\
\hline LIG Mean & & 22.95 & 28.04 & 6.63 & 7.01 & 16.31 & 21.04 & 11.24 & 15.68 & 5.08 & 5.36 \\
\hline Overall Mean & & 21.13 & 26.30 & 5.52 & 6.30 & 15.60 & 20.00 & 11.52 & 16.53 & 4.08 & 3.47 \\
\hline
\end{tabular}




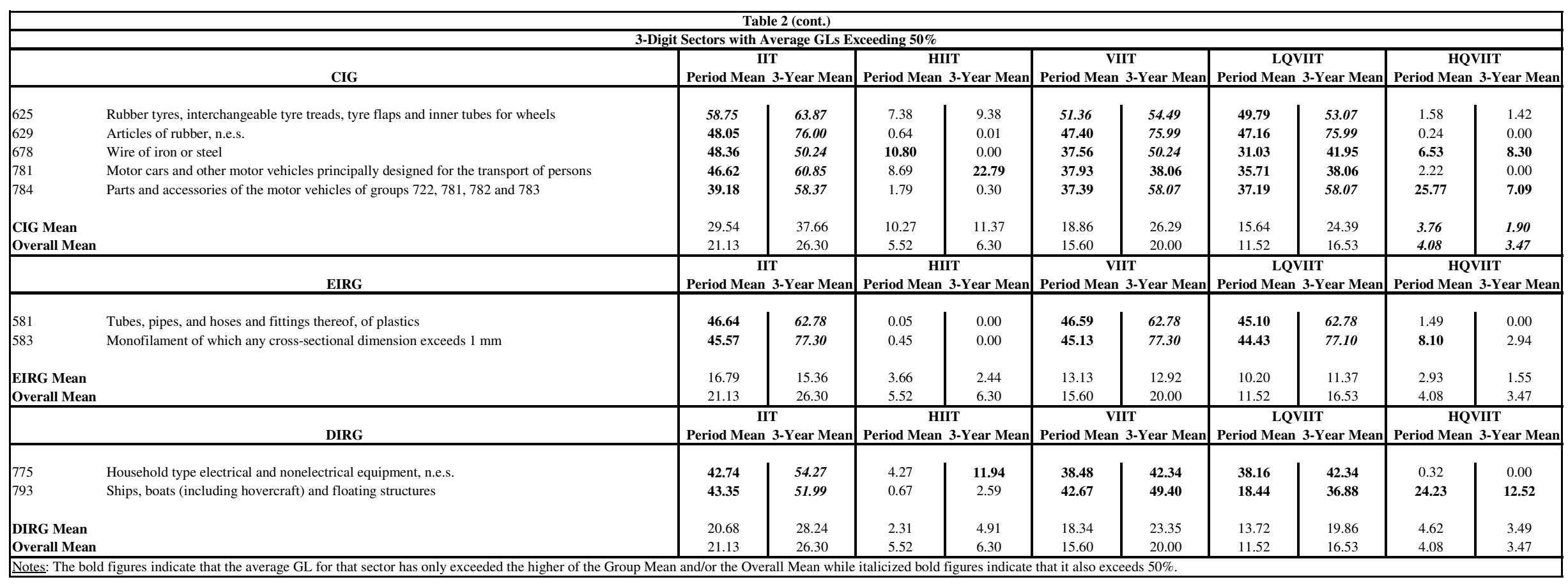


dominant for "288 Non-ferrous base metal waste and scrap, n.e.s." and "291 Crude animal materials n.e.s."

In the case of LIG, half of the sectors have GL values exceeding 50\% for both means. These are "266 Synthetic fibers for spinning", "635 Wood manufactures n.e.s.", "652 Cotton fabrics, woven”, "653 Fabrics woven, of manmade textile materials”, "666 Pottery”, "691 Structures and parts of structures n.e.c. of iron, steel or aluminum”, "692 Metal containers for storage or transport", "811 Pre-fabricated buildings", and " 821 Furniture and parts thereof". For these nine sectors, VIIT is dominant in seven of them; 635, 653, 666, 691, 692, 811 and 821. HIIT is dominant in 266 and becomes dominant in the last three years for 652. In the seven VIIT-dominant sectors LQVIIT dominates except in 635 where HQVIIT and LQVIIT are at almost the same level. Of the remaining sectors, HIIT dominates in "654 Other textile fabrics, woven". LQVIIT is dominant in all the remaining sectors.

Of the five CIG sectors only "625 Rubber tyres, etc." has an average GL value that exceeds $50 \%$ for the period as a whole and for the last three years. LQVIIT is dominant in this case; in fact, it is dominant in all five cases.

There are two sectors each in EIRG and DIRG and the average GL values of none of these sectors exceed $50 \%$ for the period as a whole and LQVIIT is dominant in all of them.

\section{Conclusions}

1. At the highest level of aggregation, namely, at the country level, we found that IIT showed a steady increase from 1993 onwards and reached its highest level (for 1987-2001) at the end of the period.

2. In terms of the rate of IIT for the five subgroups, we found that the rates for capitalintensive goods and labour-intensive goods were above that for total IIT after 1998. The rates of IIT for raw-material intensive goods and easy-to-imitate research-intensive goods were below that of total IIT.

3. The decomposition into vertical and horizontal components showed almost a uniform picture for total and subgroup IIT; VIIT dominated HIIT in all cases.

4. As to the decomposition of VIIT into high and low-quality components; we note that LQVIIT dominates and show a steady increase from 1993 onwards. It is difficult to say the same thing for HQVIIT which shows a decline from 1989 onwards and falls below the rate of HIIT after 1992. 
5. The dominance of LQVIIT is also evident in the subgroups but the patterns vary between subgroups. In case of REMIG the dominance is almost for the whole period as it is for EIRG and DIRG but for LIG the dominance is taken over by HIIT for 1991-1993. Similarly for CIG, HIIT is dominant for 1988, 1989, 1993 and 1999.

6. It is interesting to note that HQVIIT exhibits the lowest level for this period, both for total IIT and for the subgroups except DIRG where it dominates HIIT except for 2000. One does, however, observe a growth in its level from 1999 onwards in almost all cases. What we observe for HQVIIT for most of the period is the reverse of what has been observed for the UK (Greenaway et. al, 1995), Spain (Blanes and Martin, 2000) and Portugal (Crespo and Fontoura, 2004), where HQVIIT steadily increases and even overtakes LQVIIT. Whether what we observed for Turkey beginning in 1999 will develop into a similar trend is yet to be seen.

7. When we consider the 3 -digit sectors with IIT rates exceeding $50 \%$ we find that the highest number of such sectors is in LIG with RMIG coming in second. What is interesting to note, however, is that CIG and DIRG, which have IIT levels higher than total IIT, only have 5 and 2 sectors, respectively, with average GL values greater than 50\% and only in the last three years. Of course, the number of sectors with average GL levels exceeding the average overall GL or three-yearly GL are high in these two subgroups and this is not surprising in view of our remarks in item (2) above. In terms of decompositions, we note that, in all 3-digit sectors given in Table 2, VIIT and its low-quality component dominates, except for "248 Food, etc." and "291 Crude animal materials, n.e.s." in RMIG where HQVIIT dominates, "652 Cotton fabrics, etc." and "654 Other textile fabrics, woven" in LIG where HIIT dominates.

8. The fact that the rate of total IIT does not exceed $30 \%$ for the period under study is further confirmation of the conclusion we had reached in Erlat and Erlat (2003) that Turkish trade is dominated by its inter-industry component. It is also interesting to find that the progress of VIIT and HIIT for the period under study appears to mirror the trend in world trade obtained in a recent study by Fontagné, Freudenberg and Gaulier (2006). They consider a period similar to ours, namely, 1989-2002 and they also find that VIIT dominates HIIT, showing a steady growth until 1998. 


\section{Appendix}

$\underline{\text { Raw Material Intensive Goods }}$

SITC 0 Food and Live Animals

SITC 2 Crude Material, Inedible, Except Fuels (excluding 26)

SITC 3 Mineral Fuels, Lubricants and Related Materials (excluding 35)

SITC 4 Animal and Vegetable Oils, Fats and Waxes

SITC 56 Fertilizers (Other Than Those of Group 272)

\section{Labour-Intensive Goods}

SITC 26 Textile Fibres (Other Than Wool Tops and Other Combed Wool) and Their Wastes (Not Manufactured Into Yarn or Fabric)

SITC 6 Manufactured Goods Classified Chiefly by Material (excluding 62, 67, 68)

SITC 8 Miscellaneous Manufactured Articles (excluding 88, 87)

\section{$\underline{\text { Capital-Intensive Goods }}$}

SITC 1 Beverages and Tobacco

SITC 35 Electric Current

SITC 53 Dyeing, Tanning and Colouring Materials

SITC 55 Essential Oils and Resinoids and Perfume Materials; Toilet, Polishing and Cleansing Preparations

SITC 62 Rubber Manufactures, n.e.s.

SITC 67 Iron and Steel

SITC 68 Non-Ferrous Metals

SITC 78 Road Vehicles (Including Air-Cushion Vehicles)

$\underline{\text { Easy-to-Imitate Research-Intensive Goods }}$

SITC 51 Organic Chemicals

SITC 52 Inorganic Chemicals

SITC 54 Medicinal and Pharmaceutical Products

SITC 58 Plastics in Non-Primary Forms

SITC 59 Chemical Materials and Products, n.e.s.

SITC 75 Office Machines and Automatic Data-Processing Machines

SITC 76 Telecommunications and Sound-Recording and Reproducing Apparatus and Equipment

\section{Difficult-to-Imitate Research-Intensive Goods}

SITC 57 Plastics in Primary Forms

SITC 7 Machinery and Transport Equipment (excluding 75, 76, 78)

SITC 87 Professional, Scientific and Controlling Instruments and Apparatus, n.e.s.

SITC 88 Photographic Apparatus, Equipment and Supplies and Optical Goods, n.e.s.; Watches and Clocks 


\section{References}

Abd-el-Rahman, K. (1991): "Firms' Competitive and National Comparative Advantages as Joint Determinants of Trade Composition", Weltwirtschaftliches Archiv, 127(1), 8397.

Aturupane, C., S. Djankov and B. Hoekman (1999): "Horizontal and Vertical Intra-Industry Trade Between Eastern Europe and the European Union”, Weltwirtschaftliches Archiv, $135(1), 62-81$

Blanes, J.V. and C. Martin (2000): "The Nature and Causes of Intra-Industry Trade: Back to the Comparative Advantage Explanation? The Case of Spain", Weltwirtschaftliches Archiv, 136(3), 423-441.

Crespo, N. and M.P. Fontoura (2004): "Intra-Industry Trade By Types: What Can We Learn From Porteguese Data?", Review of World Economics, 140(1), 52-79.

Erk, N. and Y. Tekgül (2001): "Ekonomik Entegrasyon ve Endüstri-İçi Ticaret: Türkiye-AB Ülkeleri Arasındaki Endüstri-İçi Ticaretin Ölçülmesi ve Ticaret Tipinin Belirlenmesi." Paper presented at the METU Conference on Economics V, Ankara, Turkey on September 10-13, 2001

Erlat, G. and H. Erlat (2003): "Measuring Intra-Industry and Marginal Intra-Industry Trade: The Case for Turkey", Emerging Markets Finance and Trade,.39(6), 5-38.

Erlat, G. and H. Erlat (2006): "The Pattern of Turkish Foreign Trade: The Case for Turkey". Paper presented at the $26^{\text {th }}$ Annual Conference of the Middle East Economic Association, January 6-8, 2006, Boston, USA.

Fontangé, L. and M. Freudenberg (1997): “IIT: Methodological Issues Reconsidered”. CEPII Working Paper 97/02, Centre d'Études Prospective et d'Information Internationale, Paris.

Fontangé, L., M. Freudenberg and G. Gaulier (2006): “A Systematic Decomposition of World Trade into Horizontal and Vertical IIT". Review of World Economics, 142(3), 459475.

Greenaway, D. and C. Milner (1983): "On the Measurement of Intra-Industry Trade", Economic Journal, 93, 900-908.

Greenaway, D., R. Hine and C. Milner (1994): "Country Specific Factors and the Pattern of Horizontal and Vertical Intra-Industry Trade in the UK", Weltwirtschaftliches Archiv 130(1), 77-100.

Greenaway, D., R. Hine and C. Milner (1995): "Vertical and Horizontal Intra-Industry Trade: A Cross-Industry Analysis for the United Kingdom", Economic Journal, 105, 15051518.

Greenaway, D., C. Milner and R.J.R. Elliott (1999): "UK Intra-Industry Trade with the EU North and South", Oxford Bulletin of Economics and Statistics, 61(3), 365-384. 
Grubel, H.G. and P.J. Lloyd (1971): “The Empirical Measurement of Intra-Industry Trade.” Economic Record 47: 494-517.

Hufbauer, C.G. and J.C. Chilas (1974): "Specialization by Industrial Countries: Extent and Consequences" in H. Giersch (ed.): The International Division of Labour: Problems and Perspectives. International Symposium. Tubingen, Germany: J.C.B. Mohr, 3-38.

Lohrmann, A.M. (2002): “A Dynamic Analysis of Turkey's Trade with the European Union in the 1990s", Russian and East European Finance and Trade, 39(2), 44-58.

Y1lmaz, B. (2002): “Turkey's Competitiveness in the European Union. A Comparison of Greece, Portugal, Spain and the EU/12/15", Russian and East European Finance and Trade, 38(3), 54-72. 